
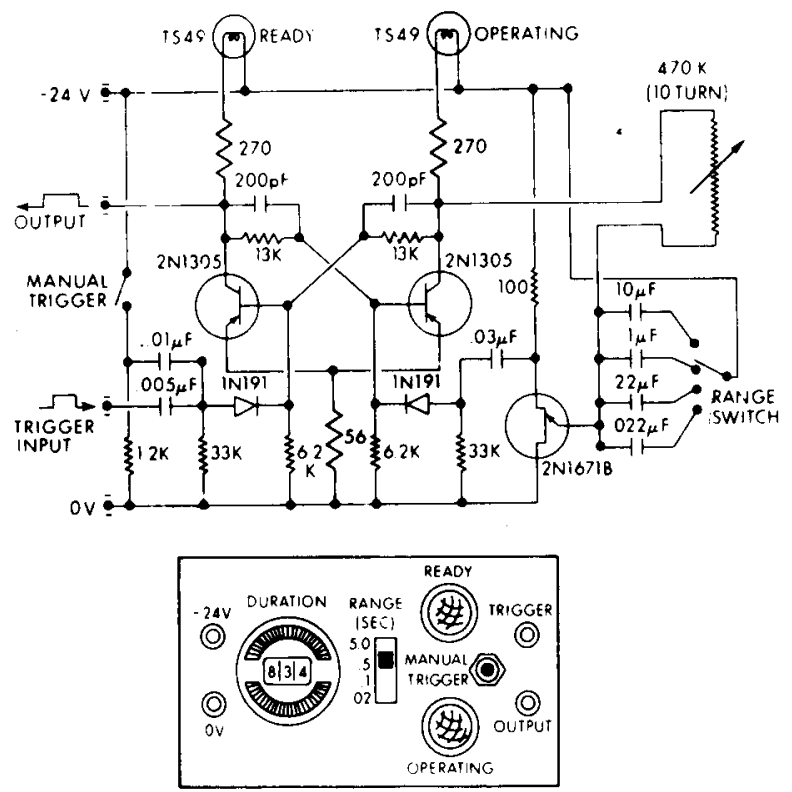

Fig. 1. Circuit diagram and front panel layout of timer.

charges, through the $470 \mathrm{~K}$ potentiometer, the selected unijunction biasing capacitor. When the charge on the biasing capacitor reaches the emitter firing potential, it briefly causes the unijunction to conduct. This results in a positive-going voltage that briefly stops the right $2 \mathrm{~N} 1305$ from conducting. As a result, the left 2 N1305 starts conducting again. This ends the negative voltage at the "output," keeps the right 2 N1305 nonconducting, and indicates that the circuit is "ready" to function again.

The modified circuit was tested to determine its stability in generating negative pulses with durations ranging from 1 to $5000 \mathrm{msec}$. Duration of the timer pulses was measured by a TSI Aptimeter Model 361 digital clock. Stability of the power supply was found to be a critical factor. During the tests and in subsequent use, the timers were powered by a Harrison Labs Mode 865 constant-voltage supply. Moment-to-moment variability was less than $1 \%$, while reset and week-to-week variability were less than $1 \%$ over the entire range of durations.

Eight identical timers of this design were built. In use, each timer was individually calibrated with a Tektronics Model 503 oscilloscope. During periods of several months' use, the timers showed no change in calibrations. When the timers were incorporated into new experiments, recalibrations were made to produce different duration settings as required. These timers have functioned for hundreds of hours over a 3-year period without failure except to replace two indicator lamps.

\section{$\operatorname{cosT}$}

The cost of parts for each unit was about $\$ 40.00$. The 10-turn potentiometer and precision dial comprised more than half of this amount. For applications which require no change in time duration, a simple 1-turn potentiometer (e.g., Clarostat Series RV4, 2-W carbon, 350K) and a knob would be sufficient and would cut the parts cost in half.

Each timer took about $8 \mathrm{~h}$ for a nontechnician to build. This time could be reduced. Humblet's layout was modified with a printed circuit application in mind. Printed circuits might be worthwhile for as few as 20 timers. For a sufficient demand, an electronics firm might be prevailed upon to offer circuit cards.

\section{REFERENCES}

HUMBLET, M. P. Design idea: Unijunction transistor multiplies monostable's pulse width. In S. Weber (Ed.), Modern digital circuits New York: McGraw-Hill, 1964. Pp. 70-71.

NILSSON, T. H. Two-pulse interval vision thresholds. Journal of the Optical Society of America, 1969, 59, 753-756.

\section{NOTE}

1. The author wishes to thank J. Brugman for his technical advice and for making available the facilities of Technical Services of the University of Alberta for construction and testing of these timers.

\title{
A technique for the construction of discrete dichotic stimulation material
}

\begin{abstract}
AUBREY J. YATES, PETER J. SMITH, BRYAN D. BURKE, and MAUREEN A. KEANE, UNIVERSITY OF WESTERN AUSTRAIIIA, Nedlands, Western Australia
\end{abstract}

Procedures are described for the generation, synchronization, and accurate spacing of discrete dichotic stimulation material. $A$ suggested standard definition of interpair interval is proposed.

The dichotic stimulation technique (the presentation of separate material simultaneously to each ear) has been extensively used since the impetus provided by Broadbent's original studies. The most common procedures have involved the use of sets of pairs of digits, letters, or words.

One of the important independent variables in the majority of these studies has been the rate of stimulus presentation. And this involves two problems: (I) the synchronization of the presentation (on stereophonic tape) of individual pairs, and
(2) the definition and achievement of a given presentation rate. A search of the literature reveals no standard solution for either of these problems. Thus, cross comparison of results of different studies is difficult.

Synchronization appears to have been achieved by recording the first digit on one channel and then attempting to line up the second digit on Channel 2 while monitoring the first by ear. With respect to the second problem, there appears to be little agreement as to what defines a given presentation rate. The rate is usually reported as the presentation of a given number of digit pairs in a given unit of time (e.g., two pairs per second). But the operations involved are seldom clear. Broadbent (1958), for example, states that "a pair of call signs arrived only every two seconds [p. 211]," and (1954) that "a $1 / 2$-sec interval was used between digits or pairs [p. 194]."

The techniques described in this paper are intended to provide: (1) a standard definition of the interpair interval, (2) methods for 
matching pairs of stimuli for presentation time and intensity level, and (3) methods for achieving a given interpair interval.

\section{GENERATION OF STIMULUS MATERIAL}

The stimulus material may be generated by a simple, specially developed computer program, RASER, using the monosyllabic numbers "one" to "ten" (excluding "seven"). The numbers are generated randomly with two restrictions: No number may appear simultaneously on each channel; only one number may be repeated, and then only once, on any channel. The maximum list length generated with this program is 10 pairs. Most studies do not exceed 6 pairs of stimuli.

\section{MATCHING PAIRS OF DIGITS ON TAPE}

The basic requirements are that the pairs commence and terminate within specified error limits, and that they be matched for intensity level. A speaker's output is monitored using a Bruel and Kjaer sound pressure level meter, Type 2603. With constant monitoring of the level meter, the speaker is trained to utter all digits at approximately equal intensity. When the speaker has learned to control the intensity of his voice, a number of recordings are made. Each digit in the list is recorded approximately 20 times. The recordings are then played through a Bruel and Kjaer sound pressurc level recorder, Type 2305, and a graphical record of the intensity of each digit obtained. One example of each number is then chosen so that the final list contains only numbers of equal intensity. Intensity is defined as the RMS pressure values over the syllable production.

The duration of each "digit is measured by a Kay Electric Company Type B/65 Sonagram. With a trained speaker who endeavors to maintain a constant intensity and duration for each number, durations range from 407 to $553 \mathrm{msec}$. Some variation is necessary if maximum intelligibility is to be preserved, since numbers have natural durations. Each number in the final list is cut out of the tape and spliced into a loop. Visual identification of number loops is aided by the use of colored leader tapes. Employing a 3M Tape Viewer, each loop is marked with splicing tape a constant distance from the commencement of the signal.

To record the numbers on stereophonic tape (one number on each channel), two Phillips monaural recorders, Type EL 3549A/00 are linked together with a junction box and fed to an Ampex stereophonic tape recorder, Type AG-350. Since a difference between the tape transports of the two monaural recorders increases the discrepancy between the commencement of the two signals, it is advisable to put the markers only a small distance-from the commencement of the signal. When the markers on the tape loops are lined up with markers on the monaural recorders, the signals are a short, constant distance from the playback heads. The two monaural recorders are set in the "pause" position. The stereo tape recorder is then set to "record" and the tape transport set in motion. The pause buttons of the two monaural recorders are released simultancously. allowing the two numbers to be recorded, one on each channel of the stereo recorder.

To test the temporal discrepancy between the commencement of the two signals, the output of the Ampex AG-350 stereophonic recorder is fed to a Tektronix dual-trace storagc cathode-ray oscilloscope, Type 564, equipped with dual-trace amplifiers, Type 3A72, and time base, Type 2B67. If the discrepancy between the pair of numbers is too largc (arbitrarily defined as greater than $20 \mathrm{msec}$ ), they are recorded again and tested until an acceptable match is obtained.

The interpair interval, or rate of presentation, can be manipulated by splicing the tape and varying the distance between signals. The interpair interval is defined as the time between the beginning of one pair of numbers and the end of the preceding pair. The definition of the beginning and end of a signal is made operationally with the aid of the Tape Viewer. The beginning of the signal is taken as the point where the signal first appears on the viewer; the end is taken as that point where the signal can no longer be detected by the same viewer. This definition must be made, since, when splicing, the only readily available method for looking at the signal is by means of the tape viewer. The beginning of the interpair interval is defined as the end of the longer of the two preceding numbers. This definition is necessary since natural duration varies between numbers. The definition could be accepted as a standard so that future studies might have common grounds for comparison.

When the recording and splicing is complete, the entire tape is re-recorded. The transcription is necessary because the original tape is weakened by the large number of splices. In this laboratory, transcription has been effected by connecting the output of the Ampex AG-350 to the input of an Ampex 2100 four-track stereophonic tape recorder. Any mismatch is climinated by appropriate setting of the input and output controls.

The technique described here involves a fair amount of operating skill. First attempts are generally unsuccessful. The skill can be learned rapidly, however, and then the results of the method are extremely accurate. CRO recordings obtained in this laboratory, after some practice by the operator, show temporal discrepancies between signals of no more than $5 \mathrm{msec}^{2}$

\section{REFERENCES}

BROADBENT, D. E. The role of auditory localization in attention and memory span. Journal of Experimental Psychology, 1954, 47, 191-196. BROADBENT, D. E. Perception and communication. Oxford: Pergamon Press, 1958.

\section{NOTE}

1. The work reported in this paper was supported by a grant from the Australian Research Grants Committee.

2. 1t is hoped to report in due course on the computer generation of dichotic lists. 